\title{
Agôn
}

Revue des arts de la scène

Critiques | Saison 2016-2017

\section{Avignon, 13 juillet : Le Sec et l'humide, de Jonathan Littell, mise en scène de Guy Cassiers}

L'objet et l'abject

\section{Caroline Châtelet}

\section{(2) OpenEdition}

Journals

Édition électronique

URL : http://journals.openedition.org/agon/4030

DOI : 10.4000/agon.4030

ISSN : 1961-8581

Éditeur

Association Agôn

Référence électronique

Caroline Châtelet, «Avignon, 13 juillet : Le Sec et l'humide, de Jonathan Littell, mise en scène de Guy Cassiers ", Agôn [En ligne], Critiques, mis en ligne le 12 juillet 2017, consulté le 23 septembre 2020. URL : http://journals.openedition.org/agon/4030 ; DOI : https://doi.org/10.4000/agon.4030

Ce document a été généré automatiquement le 23 septembre 2020.

Association Agôn et les auteurs des articles 


\title{
Avignon, 13 juillet : Le Sec et l'humide, de Jonathan Littell, mise en scène de Guy Cassiers
}

L'objet et l'abject

\author{
Caroline Châtelet
}

\section{RÉFÉRENCE}

Le Sec et l'humide, de Jonathan Littell, mise en scène de Guy Cassiers. Spectacle vu dans le cadre du Festival In d'Avignon, joué du 9 au 12 juillet à L'Autre scène du grand Avignon - Védène.

1 En découvrant Le Sec et l'humide, adaptation scénique par le metteur en scène belge Guy Cassiers de l'essai (édité en 2008) de Jonathan Littell (auteur révélé par son roman Les Bienveillantes qui remporta en 2006 le Prix Goncourt et le Grand Prix du Roman de l'Académie française), je pensais à deux choses. Un détail, et un plan large.

\section{1) Détail}

2 Je pensais à Providence ${ }^{1}$, adaptation par le metteur en scène Ludovic Lagarde du roman d'Olivier Cadiot et interprété par Laurent Poitrenaux. Créé la saison 2016-2017, ce spectacle a joué un peu partout en France (Caen, Paris, Clermont-Ferrand, Besançon, etc.). La résonance entre Providence et Le Sec et l'humide provient de la présence, dans les deux scénographies, de matériel permettant d'écouter du son via un système utilisant des bandes magnétiques.

3 Alors, certes, il y a deux appareils pour Providence, un seul pour Le Sec et l'humide, et tandis que pour le premier le personnage est dans un salon bourgeois, pour le second il s'agit d'une salle de conférence. Néanmoins, dans les deux cas l'atmosphère est cossue, 
un brin surannée aussi, et les deux enregistreurs/magnétophones inscrivent historiquement le dispositif dans une période révolue (année 60, 70 et leurs alentours). Une récurrence d'autant plus signifiante que ces deux spectacles ont été coproduit par l'Ircam - Centre Pompidou, et qu'ils développent une recherche spécifique, en lien avec cette structure, sur la présence sonore. Modifiée, remodelée, transfigurée, déstructurée, la voix devient un élément scénique à part entière, dépassant le corps de l'interprète. Or, voilà : dans les deux cas, et alors que j'imagine que l'Institut de Recherche et Coordination Acoustique/Musique produit un travail aujourd'hui essentiellement numérique, digital, le metteur en scène choisit de matérialiser sur la scène cette présence particulière, qui plus est par une fétichisation de l'objet ( $\mathrm{ah}$ le charme désuet des bandes magnétiques!). Comme si le son ne suffisait pas. Comme si au théâtre, il fallait voir les choses pour pouvoir les entendre.

\section{2) Plan large}

4 Sorti en mars 2017 au cinéma, présenté en 2016 hors-compétition au festival de Cannes ainsi que dans d'autres festivals, le documentaire Wrong Element de Jonathan Littell était consacré aux "enfants-soldats » en Ouganda. Un film intéressant par son caractère édifiant, instructif, quoique d'une facture extrêmement classique, voire, académique. Le type même d'œuvre qu'on ne regrette pas d'avoir vu pour ce qu'elle nous a appris, mais dont la forme laisse de marbre, quand elle ne sidère pas carrément par son conformisme et son respect des conventions du documentaire : alternance rigoureuse de plans de paysages, de témoignages isolés, de moments collectifs, opposition de la majesté et de la permanence de la nature et de l'instabilité des comportements humains (le tout magnifié/sublimé/amplifié par une musique classique à l'efficacité redoutable), le cadre édénique, pur, proposé soulignant la violence et la brutalité des actes commis. Et puis, avec le temps, une chose m'avait un brin chiffonné dans ce film. Cette façon dont la nature révélait la violence et venait comme essentialiser celle-ci, involontairement. Découvrant Le Sec et l'humide, la première partie du spectacle a produit le même effet initial que Wrong Element : celui, pas inintéressant, d'avoir appris un pan d'une histoire qui m'était alors inconnue et d'en recevoir une analyse. En l'occurrence, j'ai découvert la vie de Léon Degrelle, Belge engagé volontaire en 1941 dans la Wehrmacht, puis deux ans plus tard dans la Waffen-SS. Sous la forme d'une conférence, le comédien seul en scène rapporte autant les paroles de Léon Degrelle paroles sidérantes - tirées de La Campagne de Russie, texte autobiographique paru en 1949, que leur démontage.

5 Pour construire son analyse, Jonathan Littell s'appuie sur les travaux de l'historien et sociologue allemand Klaus Theweleit (auteur en 1977 de Fantasmes-mâles). Il déroule l'opposition dans le champ lexical de Degrelle du "sec", caractère éminemment fasciste (verticalité, phallisme, pouvoir) et de «l'humide » (horizontal, flou, amorphe) désignant l'ennemi russe. Pupitre, présentation du livre, extraits vidéos et sonores, costume-cravate pour le comédien, lumières dans le public : toute la panoplie du dispositif conférencier est là pour accompagner cette communication. Puis, la conférence bascule. Après avoir souligné la très faible évocation dans les écrits de Léon Degrelle de l'extermination des juifs, le conférencier quitte sa position d'orateur. S'installant à une table, visible désormais de face, il ne s'adresse plus à la salle pour livrer une analyse mais semble plutôt témoigner. Il continue de citer en alternance 
paroles de Degrelle et analyses de celles-ci, sauf qu'une distorsion formelle opère : son visage, projeté sur grand écran, se distord, tout comme sa voix se déforme. Le son se trouble, le visage en s'altérant se multiplie, devient cadavérique, cireux, et rappelle ceux des survivants des camps. Il y a là quelque chose d'obscène dans le phénomène produit par cet amalgame d'une voix, implacable, énonçant d'un ton docte des positions inhumaines et de ses visages émaciés. La fusion des victimes et du bourreau dans un même geste suscite un sentiment de malaise profond, tandis que les paroles de Degrelle, comme leur analyse, s'embourbent dans un discours répétitif - énumération des mêmes oppositions entre le sec et l'humide. Une répétition, par ailleurs, d'autant plus décevante que le nazisme a donné lieu à de brillantes déconstructions de ses discours, telle celle du philologue allemand Victor Klemperer (dans LTI, la langue du IIIe Reich, Klemperer détaille avec l'arrivée de nouveaux mots, la supplantation de termes par d'autres, la contamination des esprits par la langue).

6 Au sortir du spectacle, la lecture de l'entretien de Guy Cassiers figurant dans la feuille de salle a achevé - voire, m'a achevée - de me convaincre de l'abjection de cette proposition. Car à la question «Les écrits de Jonathan Littell, qui utilisent les mémoires d'un SS, racontent le subtil équilibre entre les parts d'humanité et de monstruosité en chacun de nous ", Guy Cassiers répond: "Effectivement, c'est cela que je tente d'explorer avec Le Sec et l'humide, par le sensible (la voix) et le sensoriel: l'idée que chacun d'entre nous pourrait être un Degrelle en puissance. Nous avons tous un monstre en nous qui se réveille selon les conjonctures et les contextes. "

\section{NOTES}

1. Critique sur Novo du spectacle Providence : https://issuu.com/media.pop/docs/novo_43/70 